\title{
Towards a contextually appropriate framework to guide counseling of torture survivors in Sub-Saharan Africa
}

\author{
Craig Higson-Smith, * * Gillian Eagle*
}

\section{Key points of interest:}

- There remains a significant gap between those treatment approaches currently described as evidencebased, and the needs and experiences of torture survivors and their counselors in sub-Saharan Africa;

- Careful, gradual exposure to traumatic memories is confirmed by both torture survivors and their counselors as the most impactful component of counseling interventions;

- Counseling interventions designed to strengthen family bonds and support torture survivors in coping with current daily stressors and threats are also felt to be highly impactful;

- Mixed methods research drawing on treatment records and personal experiences of current torture survivors offer valuable supplementary insights with respect to the delivery of evidence-based treatments in different contexts.

^) University of the Witwatersrand, Johannesburg, South Africa.

$\star \star$ ) Center for Victims of Torture, St Paul, United States of America.

Correspondence to: chigsonsmith@cvt.org

\begin{abstract}
Introduction: If the right to rehabilitation is to become a meaningful reality for torture survivors in sub-Saharan Africa, it is necessary that counseling practice be responsive to the contextual and cultural demands of the region. Recent reviews of evidence-based practice with torture survivors are discussed with a focus on those approaches developed and/or tested with torture survivors in sub-Saharan Africa.
\end{abstract}

Methods: The results of a mixed methods study of ongoing torture rehabilitation work are reported. This study incorporated a review of 85 case files of torture survivors treated at torture rehabilitation centers in three countries in sub-Saharan Africa, and in depth interviews with fifteen counsellors and fourteen clients at those same centers. Quantitative data are presented in tabular form supported by uni- and bi-variate statistical analyses as appropriate. Qualitative data are presented in terms of themes identified through emergent coding. Results and discussion: Help-seeking torture survivors in this region are a diverse and highly symptomatic group, often struggling to survive with their families in precarious circumstances and under ongoing threat. In addition to incorporating key aspects of existing evidence-based practice, counselors also use a range of psychosocial approaches to assist torture survivors to protect 
and support their families in the face of seemingly overwhelming life challenges. We propose that more systematic methodologies that facilitate the inclusion of the voices of clients and clinicians in ongoing international debates relating to evidencebased practice with torture survivors will enhance the application of such practices in diverse contexts.

Keywords: torture counseling; trauma; rehabilitation; mixed-methods; sub-Saharan Africa

Torture is practiced in many countries in sub-Saharan Africa, a problem greatly exacerbated by ongoing civil and crossborder conflicts in the region (Amnesty International, 2014; Human Rights Watch, 2017). Most countries in the region fall into the low-income bracket and have extremely limited mental health services (World Health Organisation, 2010). These countries host millions of refugees and displaced persons, including many torture survivors in desperate need of effective mental health intervention (United Nations High Commission for Refugees, 2016). In these contexts, survivors turn to a broad range of health systems, often in parallel. Such medical pluralism includes traditional and faith-based healing systems, public and private health services, as well as more specialist clinics designed to meet the particular needs of torture survivors (Olsen \& Sargent, 2017). It is essential that African researchers and practitioners adapt their models of intervention with torture survivors to the particular demands and resources of our continent while remaining cognizant of the available evidence-base on effective practice.

In this paper we summarize previously published findings from a mixed-methods study of the client populations and counseling work of three specialist torture rehabilitation centers in Cameroon, Kenya and South Africa. To this summary we add a qualitative analysis of the specific therapeutic interventions noted by torture surviving clients and their counselors as having been particularly effective in furthering rehabilitation. The results show some significant divergence from currently accepted evidence-based practice, divergence that we argue springs from the particular context of torture survivors in sub-Saharan Africa. We note that much of what we discuss in this paper might have relevance for other parts of the developing world but leave it to practitioners and researchers from other regions to assess the value of our work in their contexts.

Article 14 of the Convention Against Torture and Other Cruel, Inhuman or Degrading Treatment or Punishment (United Nations General Assembly, 1984) promises torture survivors the right to redress including rehabilitation, specifically:

... the restoration of function or the acquisition of new skills ... to enable the maximum possible selfsufficiency and function ... and may involve adjustments to the person's physical and social environment. Rehabilitation should aim to restore ... independence, physical, mental, social and vocational ability and full inclusion and participation in society. (United Nations Committee Against Torture, 2012, Paragraph 11)

The question then arises as to the most effective means by which this restoration of function might be achieved in different contexts. At least within the mental health and counseling arenas, answering this question relates to what is most strongly indicated in terms of evidence-based practice (EBP), or,

... the integration of the best available research with clinical expertise in the 
context of patient characteristics, culture, and preferences. (American Psychological Association, 2005, p. 5)

This definition requires that empirical evidence be weighed within the parameters of various contextual features, including the availability of skilled practitioners, economic and security conditions, and local attitudes and norms.

\section{Evidence-based practice for rehabilitation of torture survivors}

A Cochrane Review of research on interventions for the psychological health and well-being of torture survivors lists only nine randomized control trials (RCTs) that met standard inclusion criteria (Patel, Kellezi \& De C. Williams, 2014). The reviewers found no immediate benefits from psychological therapies in comparison with control groups, but noted some moderate benefits in reducing PTSD symptoms and distress six months after the end of treatment. They concluded that the evidence does not support the use of any particular intervention over others.

Another review of torture treatment outcomes cast a broader methodological net and included 88 treatment outcome studies (Weiss et al., 2016). These reviewers concluded that cognitive behavior therapy (CBT) that included exposure components was best supported by the research for reducing symptoms of post-traumatic stress disorder (PTSD), depression and anxiety in survivors of torture. They noted that Narrative Exposure Therapy (NET), Interpersonal Therapy (IPT), pharmacotherapy (alone or in combination with CBT), and multi-disciplinary approaches also showed promise, warranting further research.

Some treatment outcomes studies have been conducted in sub-Saharan African contexts. Igreja, Kleijn, Schreuder, van Dijk, and Verschuur (2004) demonstrated the positive impact of a single session testimony approach with rural survivors of the Mozambican civil war. Studies have examined the efficacy of NET for the treatment of PTSD in various populations in Uganda (Neuner et al., 2008), Rwanda (Schaal, Elbert and Neuner, 2009) and South Africa (Hinsberger et al., 2017) with encouraging results. In the Democratic Republic of Congo (DRC), cognitive processing therapy was shown to reduce the incidence of depression, anxiety and PTSD symptoms among female survivors of sexual violence (Bass et al. 2013). Mpande et al. (2013) tested the Tree of Life intervention, an approach that draws heavily on Zimbabwean cultural beliefs and practices, and demonstrated positive impact.

Despite these and other studies, it is disappointing that after decades of treatment outcome research, the guidance to practitioners working with torture survivors in sub-Saharan African remains equivocal. The global literature is sparse and dominated by studies of refugees resettled in Europe and North America, not the contexts in which the majority of torture survivors are located. Many interventions have not been rigorously tested and the existing studies have significant methodological flaws (Patel et al., 2014). Most importantly, the focus on symptom reduction falls short of the vision of rehabilitation described in UNCAT. In this paper we hope to contribute to the development of treatment approaches by examining the characteristics of torture survivors seeking treatment in sub-Saharan Africa, and by exploring what they and their counselors experience to be the most helpful therapeutic interventions. 


\section{Method}

This mixed-methods study consisted of two distinct parts which are combined during analysis and interpretation. The first part was a quantitative and qualitative analysis of randomly selected case files documenting the mental health treatment of 85 torture survivors. The second was a qualitative analysis of semi-structured narrative interviews with 15 counselors and 14 torture surviving clients (see Table 1 below). Case files, counsellors and clients were selected from three specialist torture rehabilitation centers in sub-Saharan Africa: the Centre for Rehabilitation and Abolition of Torture (CRAT) in Cameroon; the Independent Medical Legal Unit (IMLU) in Kenya; and the Centre for the Study of Violence and Reconciliation (CSVR) in South Africa. By selecting centers in diverse parts of the continent we hoped to capture something of the political, economic, cultural and linguistic breadth of sub-Saharan Africa.

The Ethics Committee for Research on Human Subjects of the University of the Witwatersrand, South Africa approved the research protocol. Some results from this study have been published previously
(Higson-Smith, 2013; Higson-Smith, 2014; Higson-Smith \& Eagle, 2017).

\section{Case file review}

Clinical records for 33 clients were selected from each of the three centers, on an interval basis from consecutive lists. Fourteen cases did not meet the UNCAT definition of torture and were excluded, producing a final combined sample of 85 cases.

Case files included a comprehensive psychosocial intake assessment that included demographic details such as legal status, work authorization, past and current occupations, income and housing situation, family structure and dependents, as well as brief summaries of current medical conditions, injuries, and prescription medications. A brief history of traumatic experiences, including torture, was also recorded, as well as items relating to the clients expressed needs and reasons for seeking treatment. Centers routinely administered clinical assessment measures and practitioners documented subsequent meetings with clients whether for the purposes of counseling or associated tasks such as referral or assessment. These

Table 1: Sociodemographic characteristics of the three study samples

\section{Case files reviewed}

Key respondent interviews

\begin{tabular}{lrrr} 
& & Counselors & Clients \\
\hline $\begin{array}{l}\text { Total N } \\
\text { Gender }\end{array}$ & 85 & 15 & 14 \\
$\quad$ Men & $39(46 \%)$ & $4(27 \%)$ & $8(57 \%)$ \\
$\quad$ Women & $46(54 \%)$ & $11(73 \%)$ & $6(43 \%)$ \\
Country of contact & & & \\
$\quad$ Cameroon & $30(35 \%)$ & $6(40 \%)$ & $4(29 \%)$ \\
$\quad$ Kenya & $23(27 \%)$ & $5(33 \%)$ & $6(42 \%)$ \\
$\quad$ South Africa & $32(38 \%)$ & $4(27 \%)$ & $4(29 \%)$
\end{tabular}


annotations also mentioned major events in the client's life including changes in asylum status, housing conditions, bereavements, illnesses and medical care, and further experiences of victimization.

Case files were analyzed using a range of quantitative and qualitative codes that encompassed demographic indicators; duration and frequency of counseling sessions; the current status of the therapeutic work; key features of reported torture, trauma, and loss; expressed reasons for seeking assistance; the range, severity and number of psychological and somatic symptoms reported; as well as observations regarding obstacles or advances in therapeutic progress. Using iterative thematic analysis (Braun and Clarke, 2006) we searched across individual case files to identify repeated patterns of meaning or themes in an inductive manner. Themes were coded at an explicit (or semantic) level to ensure that the coding system remained strongly "data-driven." Initial codes were developed on site in the three torture treatment centers where the original analysis was conducted. Codes were subsequently reviewed and refined across the entire data set to ensure standardization of coding. Where appropriate, basic uni- and bivariate statistics were calculated to describe the composition of the sample and to highlight differences between groups within the sample.

This adult sample ranged from 18 to 66 years $($ mean $=33.9, \mathrm{sd}=10)$ with no significant difference between the samples from the three centers. Further demographic details are presented in Table 2.

\section{Interviews with counselors}

The first author invited staff who provided counseling at the centers to participate in semi-structured interviews relating to their counseling practice. All 15 counselors working at the centers accepted this invitation. Interviews were conducted in English and included questions about counselor's training and experience, personal motivation for work with torture survivors, emotional well-being, and approaches and methods used in counseling. Average interview length was 57 minutes. During the interviews counselors were asked to think of two or three specific clients for whom they considered the therapeutic work to have been particularly helpful. They were then asked to narrate the story of their work with those clients. In the course of their narrations, respondents were asked to identify particularly helpful therapeutic interventions that enabled the client to take a significant step forward in his or her recovery.

The counselors interviewed ranged in age from 25 to 65 years and all but one were citizens of the country in which they were working. Six were clinical psychologists, four were general nurses, three were social workers, one was a psychiatric nurse, and one was a general medical practitioner. The aggregate term "counselor" is used to describe this diverse group and the activity that is the focus of this study. These counselors had a median of ten years work experience (ranging from one to thirty years). Their experience in torture rehabilitation specifically was shorter (one to 22 years with a median of 6 years). In addition to their professional training, all had participated in one or more shorter training courses on evidence-based approaches to counseling people who have survived torture. The first author had worked for several years with the selected centers in a capacity building role, covering topics including evidence-based treatments for PTSD, effects of trauma on the brain, arousal regulation skills, CBT and trauma-focused counseling skills, treatment planning, conducting clinical 
Table 2: Demographic characteristics of case review sample by participating center

\begin{tabular}{|c|c|c|c|c|}
\hline & CRAT & IMLU & CSVR & $\begin{array}{l}\text { Total } \\
\text { Sample }\end{array}$ \\
\hline & $\mathbf{n}=\mathbf{3 0}$ & $n=23$ & $\mathrm{n}=32$ & $\mathrm{~N}=85$ \\
\hline \multicolumn{5}{|l|}{ Gender } \\
\hline Men & $14(47 \%)$ & $12(52 \%)$ & $13(41 \%)$ & $39(46 \%$ \\
\hline Women & $16(53 \%)$ & $11(48 \%)$ & $19(59 \%)$ & $46(54 \%$ \\
\hline \multicolumn{5}{|l|}{ Country of origin } \\
\hline Kenya & & $22(96 \%)$ & & $22(26 \%$ \\
\hline $\begin{array}{l}\text { Democratic Republic } \\
\text { of Congo (DRC) }\end{array}$ & $9(30 \%)$ & & $11(34 \%)$ & $20(24 \%$ \\
\hline Zimbabwe & & & $14(44 \%)$ & $14(16 \%$ \\
\hline $\begin{array}{l}\text { Central African } \\
\text { Republic (CAR) }\end{array}$ & $9(30 \%)$ & & & $9(11 \%)$ \\
\hline Rwanda & $7(23 \%)$ & & $2(6 \%)$ & $9(11 \%)$ \\
\hline Chad & $4(13 \%)$ & & & $4(5 \%)$ \\
\hline Other & $1(3 \%)$ & $1(4 \%)$ & $5(16 \%)$ & $7(8 \%)$ \\
\hline
\end{tabular}

Family situation

$\begin{array}{lllll}\text { Married/partnered } & 15(50 \%) & 17(74 \%) & 13(43 \%) & 45(54 \%) \\ \text { Single } & 10(33 \%) & 2(9 \%) & 9(30 \%) & 21(25 \%) \\ \text { Widowed } & 5(17 \%) & 1(4 \%) & 5(17 \%) & 11(13 \%) \\ \begin{array}{l}\text { Divorced/separated } \\ \text { Caring for children (median } \\ \text { children = 3) }\end{array} & 20(67 \%) & 19(83 \%) & 21(70 \%) & 60(7 \%) \\ \text { Education } & & & \\ \begin{array}{l}\text { Primary incomplete } \\ \text { Primary complete }\end{array} & 2(7 \%) & 2(11 \%) & 1(3 \%) & 5(6 \%) \\ \text { Secondary complete } & 10(34 \%) & 9(50 \%) & 9(29 \%) & 28(36 \%) \\ \text { Tertiary qualification } & 13(45 \%) & 6(33 \%) & 10(32 \%) & 29(37 \%) \\ & 4(14 \%) & 1(6 \%) & 11(36 \%) & 16(21 \%)\end{array}$

Current employment

$\begin{array}{lllll}\text { Unemployed } & 18(60 \%) & 6(31 \%) & 15(50 \%) & 39(49 \%) \\ \text { Informal employment } & 8(27 \%) & 10(53 \%) & 5(17 \%) & 23(29 \%) \\ \text { Artisans / skilled labor } & 3(10 \%) & 3(16 \%) & 8(27 \%) & 14(18 \%) \\ \text { Professional } & & & 1(3 \%) & 1(1 \%) \\ \text { Student } & 1(3 \%) & & 1(3 \%) & 2(3 \%)\end{array}$


assessments, and ethical concerns in the treatment of torture survivors. Although this existing relationship must influence counselors' responses it also provides a foundation of trust necessary for counselors to describe their true experiences of this challenging work.

\section{Interviews with clients}

Participating counselors invited clients to take part in a similar interview concerning their experience of counseling (and explicitly not about the traumatic experiences that led them to seek assistance). We invited adult clients who had experienced torture and who were at a point in their therapeutic work where counselor and client agreed that the client could participate in the interview without undue risk of re-traumatization. Fourteen clients accepted the invitation. Eight were interviewed in English and six in French with the assistance of an interpreter, a post-graduate psychology student. Average interview length was 45 minutes and included questions about access to services, obstacles in attending counseling, frequency and duration of sessions, length of intervention, as well as therapeutic experience. In particular, clients were asked to describe therapeutic moments which they felt had been most helpful to them. The first author had no previous relationship with these clients. His being a professional man of European descent associated with an international organization is likely to have influenced clients' responses in important ways.

Participating clients ranged in age from 25 to 63 years. The eight clients treated in South Africa and Cameroon were refugees or asylum seekers from other African countries. The six interviewed in Kenya were all Kenyan citizens.

\section{Qualitative analysis of interviews}

Both counselor and client interviews were translated where necessary and transcribed verbatim. For the purposes of this analysis, any content relating to successful therapeutic intervention was extracted for independent thematic analysis. A total of 125 incidents (75 from counselors and 50 from clients) ranging in length from a couple of sentences to several paragraphs were identified. Using an iterative thematic analysis process the material from the two groups was initially analyzed independently. The two sets of themes were then integrated into a final set of the 15 most salient emergent themes. These themes were labeled and described with respect to the intervention itself and the associated therapeutic intention. Thereafter, the combined set of incidents was analyzed using the 15 thematic categories. Due to the interconnected nature of the themes (and the therapeutic work itself) some incidents were coded under more than one theme. Since most counselors described successful work with several clients, the same theme sometimes emerged repeatedly in a single interview. Clients described only their own experience and so each theme was only counted once. In the final analysis we recorded how often each theme was mentioned by the two groups of respondents and how those responses were distributed across the three centers (see Table 2).

An independent researcher coded a sample of 50 incidents which were then checked for reliability against the authors' coding. Percentage agreement was $86 \%$.

\section{Results and discussion}

\section{Results of case file review}

The review of a representative sample of 85 case files showed that clients came from a wide range of countries and represented a 
broad range of ethnicities, cultural traditions and languages. Such diversity demands a high degree of cultural competence from counselors, as well as the capacity to work effectively with interpreters. In some cases interpreters were employed by the centers, but at times interpretation was provided by friends or family of the client. This has important consequences for what is possible in counseling.

An analysis of the specific torture experiences reported divided clients into several groups. Approximately $40 \%$ were people who had been caught up in a civil conflict in the region. They were tortured as part of forced conscription, as punishment for alleged support of the enemy, to coerce them into providing supplies to militias, or because of their ethnic or religious identity. Approximately $35 \%$ self-identified as activists and included political and community leaders, as well as journalists targeted by oppressive regimes. A third group comprised spouses, parents and children of activists and accounted for $18 \%$ of the sample. This group was tortured to punish their family members or to extract information about those peoples' whereabouts or activities. Finally, the sample included several people (7\%) who had been accused of a crime and tortured as part of a police investigation or as punishment. The varied circumstances under which torture occurred has profound implications for counseling, impacting the possibility of finding safety, the availability of support within families and communities, as well as ways in which clients are able to construct meaning.

Fifty-five percent of clients receiving counseling did not originally approach the centers for mental health care. More commonly clients sought medical or social welfare assistance. This has profound implications for the manner in which clients are introduced to mental health services, their understanding and expectations of services, the way in which initial assessments are conducted, as well as for sustained client engagement.

The course of treatment recorded in the client files varied greatly in complexity and length. The number of counseling sessions attended ranged from 1 to 60 . However, the distribution was highly skewed with a median of 3.5 sessions. Very few clients $(11 \%)$ received the 12 or more sessions of treatment found to be optimal (Weiss et al., 2016) and only $39 \%$ of the files reviewed reported the counseling process ending in a planned or negotiated manner. Most clients stopped attending counseling without explanation after fewer than three meetings. A range of explanations for such low completion rates have been advanced, including difficulties in reaching service delivery sites, the cost of transport, challenges in managing the care of small children, moving away to pursue employment or safer living conditions, and the loss of time to income generating activities. Nevertheless, we must also consider the possibility that some clients felt that the benefit of the first few sessions of counseling was not worth the effort of attending. Counseling models adapted to the sub-Saharan African context must grapple with questions of motivation for counseling, and develop strategies to increase access and engagement.

Regardless of engagement, clients reported high levels of distress and symptomatology relating to depression, anxiety and PTSD. The most common complaints included pervasive worries $(72 \%)$, intrusive thoughts and memories (70\%), sleep difficulties (69\%), and low mood (59\%). Many clients (66\%) reported somatic complaints without a clear medical 
cause. It can be difficult to determine whether non-specific but chronic somatic complaints (including generalized pain, weakness and fatigue, and a weakened immune response) arise from physical damage caused by prolonged torture and incarceration in poor conditions, or have their origins in emotional distress (de C Williams \& Baird, 2016). Such determinations are further complicated in sub-Saharan Africa where emotional distress is often communicated through idioms rooted in the body (Ventevogel, Jordans, Reis \& de Jong, 2013).

The majority of case files reviewed was of younger adults, married and/or caring for children. Twenty-eight percent were citizens of the country in which they sought help, but many more were refugees $(25 \%)$, asylum seekers $(32 \%)$, or undocumented persons (15\%). Citizens were also often displaced, having been driven out of rural communities and forced to seek refuge in the relative anonymity of larger urban areas. Refugees, asylum seekers and undocumented people reported many more symptoms than citizens and we speculate that this is due to the confluence of past traumatic experiences and ongoing threat. Asylum seekers and undocumented people must cope with the continuous fear of being incarcerated and/ or returned to the country where they were originally tortured. Refugees and internally displaced people must at times cope with being an outsider in openly hostile host communities. This hostility is expressed on a daily basis in interactions with neighbors, as well as service providers and police. At times it spills over into physical attacks on foreigners, their homes and businesses.

An analysis of accounts of current danger identified five types of continuing threat: harassment by the original torturers or their colleagues; harassment by government officials unrelated to the original torture; threats from neighbors and other members of the community; domestic violence; and gender-based violence. The presence of ongoing threat in all these forms is another important consideration in counseling torture survivors, one that is often neglected in counseling models developed in more protective contexts.

Forty-six percent of the cases reviewed disclosed a significant recent bereavement, the majority of which were violent ( $85 \%)$. Thirtynine percent of the bereaved group reported being directly victimized during the event in which their loved one died. Such victimization included torture, rape, and intimidation. In many cases the client was directly implicated in the violent death of their loved one. For example, the loved one died trying to protect the client,from torture linked to the client's political activism. Bereaved clients reported significantly elevated depression-related symptoms (effect size $=0.65$ ) and increased suicidal ideation (odds ratio $=4.99$ ). Current assessment batteries do not assess for complicated bereavement and counseling models used with torture survivors seldom address grief explicitly.

These results paint a picture of a highly diverse population of treatmentseeking torture survivors on the continent. They are a highly symptomatic group having often survived complex and repeated victimization, including violent bereavement. Many are struggling to survive in precarious circumstances or under active, ongoing threat. These factors impede access to services and undermine progress in rehabilitation. In the next section we examine what a sample of clients and their counselors describe as the most significant components of their therapeutic work. 
Results of interviews with counselors and clients - most helpful therapeutic interventions The qualitative analysis of incidents of therapeutic change narrated by clients and counsellors resulted in a set of interconnected themes which are summarized in Table 3 and elaborated below.

The theme mentioned by most respondents (both clients and counselors) was trauma exposure work, a theme that aligns well with existing EBP recommendations. The salience of this theme supports the position that a focus on past traumatic experiences is important in work with torture survivors in sub-Saharan Africa. While counselors emphasized the integration of traumatic memories and the empathic witnessing of gross human rights violations, clients were more likely to emphasize the cathartic benefits, describing the pain of telling and the relief that followed. A middle aged man who fled to South Africa after being tortured in Zimbabwe described his experience as follows:

In the beginning it is difficult to tell or retell the story. Because initially you just browse the story without going into, into details. And then you tell it the second and third. And then when you are now settled you actually tell the story as it is and with all the details. Whatever, actually telling the story with your heart and actually seeing, visualizing what has been happening. You can feel that there is an impact in you. ... It had more meaning emotionally and then after that, with some sessions and retelling details, and doing some exercise, it no longer was, it was no longer necessary.

The next two most commonly described themes were more rooted in current life challenges. That therapeutic work focused on strengthening families was important to both clients and counselors is not surprising given the proportion of clients who are married and caring for children, and the precariousness of their lives. Strain within families may result from direct traumatization, vicarious and transgenerational trauma, increased stressors due to forced migration, bereavement, and changing family roles. An older Kenyan man struggling with his wife's depression

Table 3: Therapeutic interventions most frequently described by client and counselors as particularly helpful to torture survivors

\begin{tabular}{lll}
\hline Theme & Description & Frequency \\
\hline $\begin{array}{l}\text { Trauma exposure } \\
\text { work }\end{array}$ & $\begin{array}{l}\text { Intentional, graduated retelling of trauma narratives } \\
\text { combined with active affect and arousal regulation } \\
\text { intended to integrate and habituate traumatic } \\
\text { memories. }\end{array}$ & $\begin{array}{l}7 \text { clients and } 7 \\
\text { counselors from all 3 } \\
\text { countries (14 incidents) }\end{array}$ \\
$\begin{array}{ll}\text { Strengthening } \\
\text { families }\end{array}$ & $\begin{array}{l}\text { Interventions intended to strengthen support within } \\
\text { families and reduce vicarious and transgenerational } \\
\text { trauma, including education around interpersonal } \\
\text { effects of torture, parenting support, and conflict } \\
\text { management. }\end{array}$ & $\begin{array}{l}\text { 5 clients and 5 } \\
\text { counselors from Kenya } \\
\text { incidents) }\end{array}$ \\
& $\begin{array}{l}\text { Collaborative problem solving intended to stabilize } \\
\text { the client and increase agency and self-sufficiency in } \\
\text { the face of persistent life challenges. }\end{array}$ & $\begin{array}{l}\text { 4 clients and } 6 \\
\text { counselors from all 3 } \\
\text { countries (15 incidents) }\end{array}$
\end{tabular}




\begin{tabular}{ll}
\hline Theme & Description \\
\hline Psychoeducation & $\begin{array}{l}\text { Explanations of underlying causes of distress in order } \\
\text { to normalize reactions and encourage healthy coping. } \\
\text { Explanations of counseling interventions to increase } \\
\text { engagement with treatment. }\end{array}$
\end{tabular}

\section{Symptom} management

Encouraging Spirituality

Disputing irrational beliefs

Sustaining hope

Dignity and respect

Encouraging activism and volunteer work

Case
management

Grief counseling

Support for medications

Focus on strengths

Home practice
Guidance and skills-building intended to reduce the frequency and severity of disruptive symptoms and improve global functioning.

Supporting spiritual beliefs and encouraging participation in religious practices with the intention of sustaining hope and perseverance.

Exploring and testing evidence in relation to beliefs and thought patterns (particularly in relation to helplessness and isolation) with the aim of reducing distress and building support and agency.

Holding a vision of an improved future in order to reduce hopelessness and increase agency in the face of persistent life challenges.

Treating client with respect thereby upholding human dignity, establishing a therapeutic relationship and increasing engagement, and counteracting experiences of stigma and discrimination.

Encouraging advocacy and community work of importance to the client with the intention of increasing community connection, self-esteem and personal meaning.

Identifying additional needs and referring client to other service providers with the intention of increasinges access to services and stabilizing the client.

Providing support for healthy grieving and encouraging community and private rituals of remembrance to reduce symptoms of complicated grief.

Explaining purpose and proper dosage of medications to stabilize clients and reduce physical and emotional symptoms.

Recognize and encourage use of personal strengths employed during and after traumatic experiences with the aim of improving coping and self-sufficiency.

Agreement and monitoring of key activities to be practiced between sessions with the aim of stabilizing the client, improving coping, and building selfsufficiency.
Frequency

4 clients and 6

counselors from all 3

countries (12 incidents)

4 clients and 6

counselors from all 3

countries (11 incidents)

4 clients and 5

counselors from all 3

countries (11 incidents)

1 client and 7

counselors from all 3

countries (11 incidents)

10 clients from all 3

countries (10 incidents)

6 clients and 1

counselor from all 3

countries (7 incidents)

2 clients and 4

counselors in Kenya

and South Africa (6

incidents)

6 clients in all three countries (6 incidents)

3 clients and 2

counselors in Kenya

and South Africa (5

incidents)

1 client and 4

counselors in all three

countries (5 incidents)

1 client and 4

counselors in all three

countries (f incidents)

2 counselors from

Kenya and South Africa

(4 incidents) 
and suicidal thoughts after the couple were driven from their community described the help he received as follows:

We talked about my wife and how I am experiencing because still I was sick and, still I'm thinking how I cannot sleep well because I was thinking my wife can wake up and do something terrible. But [my counselor] explains ... that the only thing she needs is care. Slowly with her I showed her I cared for her. I told her, "Okay, we can talk slowly, I never come with sharp word" or telling her anything she can be angry. And now I experience and I become okay with her. Therapeutic approaches that are too individualistic in focus may fail to address anxieties relating to family health, something that is inseparable from personal wellbeing to many people in sub-Saharan Africa.

Problem solving interventions were also often mentioned as being particularly helpful and are strongly connected to the challenges and threats in clients' daily lives. Therapeutic interventions focused solely on past trauma may be experienced as less helpful by clients who need assistance in dealing with immediate problems with important consequences for their survival. The Zimbabwean man quoted above had this to say,

I would prefer to talk about other people's problems. And, in a way, to me when I am talking other people's problems, and solving other people's problems, I would discover that I am also solving my own personal problems. They're the same.

In these words we hear not only an increased sense of control but also solidarity with others who are suffering. Problem solving is most strongly linked with the seemingly overwhelming daily stressors that so many torture survivors, particularly people who have been displaced from their communities, are living with.
Understanding of the underlying causes of mental illness and the purpose of mental health services varies greatly in sub-Saharan Africa. For this reason, psychoeducation may be more important in this context than it is in others. A Kenyan counselor described how she uses metaphors and physical objects to help clients understand and label the underlying causes of their distress.

Simple ways of understanding in

psychoeducation ... finding practical ways of educating them to understand the root cause and how it's connected to their symptoms and the reactions that they are having. Because once they understand that, it makes sense to them. Then the treatment plan, that if they try this it could help relieve [their suffering]. This counselor also links psychoeducation to the rationale for the treatment plan, implying that this is also important for client engagement in counseling.

Closely linked to psychoeducation is work on symptom management, which includes helping the client develop skills for arousal and affect regulation, as well as finding ways to cope with disruptive symptoms. A Kenyan client struggling with persistent and severe headaches described his counselor's intervention as follows:

I was coming here with headache. But [my counselor] told me there is something which I will be remembering ... He shows me how I need to, to remove that kind of headache. I only start. Find somewhere comfortable, somewhere quiet. I sit myself there. I come to relax and he shows me how I can stay relaxed somewhere. And then I experienced that my headache become low. I found that was only stress ... Yes, it goes away, yeah.

Both psychoeducation and symptom management are often included (at least implicitly) in current EBP recommendations.

Many people in sub-Saharan Africa are devout Christians or Muslims with many 
also honoring traditional African gods and ancestral spirits. A range of interventions that encouraged spirituality as a source of resilience were judged important by both clients and counselors. An older woman of strong Christian faith receiving treatment in Cameroon found it helpful that her counselor could work with her on a spiritual level too.

[I had] lost my hope. [My counselor] used to tell me that I don't have to lose my spirit. I have to continue with my faith in God. Even if the world is rejecting us, only Him, He change our situation ... so I have understand that God was above us. That is why now I am stress free. I'm stress free and I continue to do my life.

In this way the counselor is using a religious belief in divine care and protection to support the client's agency and sense of control in her life.

A related theme was that of disputing unhealthy beliefs and thought patterns, which was mentioned almost exclusively by counselors. A Kenyan counsellor describes working with a client who had lost her husband violently and whose grief had left her feeling marginalized and alone:

... to reframe "that everybody is against me, nobody wants me in this community" ... So if people came and they quickly organized about how this body can be buried, they notified her parents, they built a house for her. And the visitors who came for the burial were taken care of and all that. That was some support! So although she thought everyone hated her, that wasn't strictly true.

Serving a similar purpose were therapeutic interventions intended to sustain hope. Ten clients told us how their counselor instilled hope in them when they felt hopeless, and it is interesting to note that none of the counselors emphasizes this theme. In the words of a Kenyan woman:
From the time I was given counseling, that power I get from that time ... because all things I struggle with will come in the end ... the life is going different sometimes, sometimes it's okay. ... [My counselor] told me this problem is to test my heart whether I'm strong enough to hold these problems and I have to be strong enough to ... overpower my problems. He told me, "Never, never give up!"

These themes of encouraging spirituality, disputing irrational beliefs and sustaining hope are all associated with building clients' capacity to persevere in the face of seemingly overwhelming challenges and threats to their present survival. The emphasis is powerfully on the present and not on past traumatic experiences.

Other important themes included case management and referral, as well as assistance with medications. All three centers were able to refer clients to a range of other services and did so routinely. Services offering emergency shelter and food were typically in high demand and over-subscribed. Referral for medical and psychiatric care was also available to all centers through either government or humanitarian agencies. Medical personnel are often limited in the time they have available to explain the purpose and dosage of medications and so counselors were often called upon to explain prescriptions and encourage adherence. In contexts where clients have less familiarity with "Western" health systems, the value placed on help in navigating these complex systems is significantly greater.

Also mentioned were more general principles of care including encouraging home practice, intentionally acting to protect the clients' human dignity, and recognizing the strengths that they displayed both during and after traumatic experiences. 


\section{Limitations of this study}

This study has several limitations. Firstly, the findings are based on a narrow sample of cases drawn from only three of the multiplicity of sites across the continent at which torture survivors seek mental health and psychosocial services. Similarly, a review of 85 cases is unlikely to contain the full complexity of the challenges experienced by torture survivors in subSaharan Africa. Likewise, interviews with only 14 clients and 15 counselors cannot hope to be representative of the full range of experiences of rehabilitation in the field. Nevertheless, we hope these samples are diverse and large enough to identify key contextual challenges in the rehabilitation of torture survivors pertinent to the region.

Secondly, as with all key respondent data, the findings are dependent on the background, experience and training of the respondents. In this case and for ethical reasons, we interviewed only clients who had shown marked improvement during their time in counseling. The responses of clients who were less resilient or who had a negative experience of counselling might have been very different. Counselors' responses were also heavily influenced by their professional and subsequent training. Respondents are likely to favor interventions in which they have been trained and ignore others to which they have had limited exposure. Also, counselors' responses must be viewed within the frame of their relationships with the first author. However, it is important to remember that these are seasoned mental health and health professionals. The interview transcripts reflect informed, thoughtful and self-critical conversations about the work of torture rehabilitation in the region. With the exceptions of the emphasis on gradual exposure to traumatic memories and disputing irrational beliefs, the themes emerging from this analysis do not reflect the content of training material covered by the first author. Nevertheless, his influence as a capacity building consultant cannot be discounted. It is difficult to know how the results might have varied had a less trusted, but also less involved, person conducted the interviews.

Thirdly, the questions posed to counselors and clients were not identical and intentionally framed in broad terms. As a result, the responses include a mix of specific and non-specific factors. Specific factors, for example the recounting of traumatic memories and disputing of irrational beliefs, may be more directly relevant to debates around particular therapeutic approaches. Less specific factors, for example upholding clients' human dignity and case management, arguably apply to all competent forms of psychosocial intervention. Nevertheless, we feel they are relevant to discussions of how EBP is developed and implemented in subSaharan Africa.

Finally, the participating centers were able to conduct follow-up assessments on only a very few clients. Our analysis therefore offers no quantitative estimate of the effectiveness of the interventions discussed.

\section{Conclusions}

The strengths of this study lie in the intersection of our analysis of the profile and needs of a representative sample of the actual client population served by these clinics, with an in-depth analysis of the experience of the counseling work from the perspectives of both client and counselor. The findings emerge from the real-world of service provision, reflecting a wide range of case presentations, many of which are extremely complex, and drawing on the experience of actual counselors working in the region today. 
The results suggest that counselors working in torture rehabilitation centers in sub-Saharan Africa incorporate key aspects of currently accepted EBP into their work. Foremost among these is the work of retelling narratives of past traumatic experiences with the intention of integrating traumatic memories. However, it seems that counselors also invest a great deal of counseling time into interventions intended to assist the client to survive and to hold their families together in the face of overwhelming current stressors and threats. These interventions involve problem-solving, instilling hope through spiritual and other means, and encouraging perseverance. Counselors also spend significant time helping their clients understand and manage their emotions, reactions and symptoms, and in navigating health and social welfare systems. Clients experienced value in virtually all these interventions.

These findings suggest a significant gap between those treatment approaches currently described as evidence-based, and the needs and experiences of torture survivors and their counselors in subSaharan Africa. These counselors would benefit greatly from training and supervision in clearly articulated treatment approaches that are less focused on individual recovery from past traumatic experiences, and instead recognize that most torture survivors have lost family, property, occupation, and community and are often struggling to survive in a dangerous world with little support. Such approaches need to be accessible and rooted in African understandings of mental health and healing. Counselors also need approaches that increase clients' resourcefulness and capacity for focused action and persistence in the face of adversity, as well as tools to strengthen families' capacity to protect and nurture their members. In this way the definition of treatment outcome may be expanded into something closer to the vision of rehabilitation expressed in UNCAT.

In torture rehabilitation, as in other aspects of mental health service delivery, evidence-based practice is insufficiently informed by counselor expertise and client preferences in particular contexts. It is our hope that methodologies such as the one we have utilized in this study will assist in more systematically integrating clinical and contextual knowledge in the ongoing discourse on therapeutic effectiveness. Our goal is that these findings will encourage innovations in the structure, content and process of therapeutic approaches to torture rehabilitation that are more effective in realizing torture survivors' right to rehabilitation in our region and around the world.

\section{Acknowledgements}

We would like to acknowledge the support of the counselors and clients of the Centre for the Study of Violence and Reconciliation, the Independent Medical Legal Unit, and the Centre for Rehabilitation and the Abolition of Torture. This research was partially funded by the African Doctoral Dissertation Research Fellowship offered by the African Population and Health Research Center (APHRC) in partnership with the International Development Research Center (IDRC).

\section{References}

American Psychological Association. (2005). Report of the 2005 Presidential Task Force on EvidenceBased Practice. Washington, DC: American Psychological Association.

Amnesty International (2014). Torture in 2014: Thirty years of broken promises. London: Amnesty International.

Bass, J. K., Annan, J., McIvor Murray, S., Kaysen, D., Griffiths, S., Cetinoglu, T., Wachter, K., Murray, LK., Bolton, P. A. (2013). Controlled 
trial of psychotherapy for Congolese survivors of sexual violence. New England fournal of Medicine, 368(23), 2182-2191. http://dx.doi.org/10.1056/ NEJMoa 1211853

Braun, V., \& Clarke, V. (2006). Using thematic analysis in psychology. Qualitative Research in Psychology, 3(2), 77-101. http://dx.doi. org/10.1191/1478088706qp063oa

de C Williams, A. C. \& Baird, E. (2016). Special considerations for the treatment of pain from torture and war. Current Anesthesiology Reports, 6(4), 319-326. http://dx.doi.org/10.1007/s40140016-0187-0

Higson-Smith, C. (2013). Counseling torture survivors in contexts of ongoing threat: Narratives from subSaharan Africa. Peace $\mathcal{E}$ Conflict, 19(2), 164-179. http://dx.doi.org/10.1037/a0032531

Higson-Smith, C. (2014). Complicated grief in helpseeking torture survivors in sub-Saharan African contexts. American fournal of Orthopsychiatry, 84(5), 487-495. http://dx.doi.org/10.1037/ ort0000009

Higson-Smith, C., \& Eagle, G. (2017). Counseling Torture Survivors in Sub-Saharan Africa: How Relevant Are Current Evidence-Based Practices? Traumatology. http://dx.doi.org/10.1037/ trm0000131

Hinsberger, M., Holtzhausen, L., Sommer, J., Kaminer, D., Elbert, T., Seedat, S., Wilker S., Crombach A., Weierstall, R. (2017). Feasibility and effectiveness of narrative exposure therapy and cognitive behavioral therapy in a context of ongoing violence in South Africa. Psychological Trauma: Theory, Research, Practice, and Policy, 9(3), 282-291. http://dx.doi.org/10.1037/tra0000197

Human Rights Watch (2017). World Report 2017: Events of 2016. New York, NY: Human Rights Watch.

Igreja, V., Kleijn, W. C., Schreuder, B. J. N., van Dijk, J. A., \& Verschuur, M. (2004). Testimony method to ameliorate post-traumatic stress symptoms: Community-based intervention study with Mozambican civil war survivors. British fournal of Psychiatry, 184(3), 251-257. http://dx.doi. org/10.1192/bjp.184.3.251

Mpande, E., Higson-Smith, C., Chimatira, R. J., Kadaira, A., Mashonganyika, J., Ncube, Q. M., ... Ziwoni, N. (2013). Community intervention during ongoing political violence: What is possible? What works? Peace and Conflict, 19(2), 196-208. http://dx.doi.org/10.1037/a0032529

Neuner, F., Onyut, P. L., Ertl, V., Odenwald, M., Schauer, E., \& Elbert, T. (2008). Treatment of posttraumatic stress disorder by trained lay counselors in an African refugee settlement: A randomized controlled trial. Fournal of Consulting and Clinical Psychology, 76(4), 686-694. http:// dx.doi.org/10.1037/0022-006x.76.4.686

Olsen, W. C. \& Sargent, C. (Eds.). (2017). African Medical Pluralism. Bloomington, IN: Indiana University Press.

Patel, N., Kellezi, B., \& De C. Williams, A. C. (2014). Psychological, social and welfare interventions for psychological health and wellbeing of torture survivors. Cochrane Database of Systematic Reviews, 11, CD009317. http://dx.doi. org/10.1002/14651858.CD009317.pub2

Schaal, S., Elbert, T., \& Neuner, F. (2009). Narrative exposure therapy versus interpersonal psychotherapy: A pilot randomized controlled trial with Rwandan genocide orphans.

Psychotherapy and Psychosomatics, 78(5), 298-306. http://dx.doi.org/10.1159/000229768

United Nations Committee against Torture (2012). General Comment No.3: Implementation of Article 14 by States Parties.

United Nations General Assembly (1984). Convention against Torture and Other Cruel, Inhuman or Degrading Treatment or Punishment.

United Nations High Commission for Refugees (2016). Global trends:Forced displacement in 2015. Geneva: UNHCR.

Ventevogel, P., Jordans, M., Reis, R., \& de Jong, J. (2013). Madness or sadness? Local concepts of mental illness in four conflict-affected African communities. Conflict $\mathcal{E}$ Health, 7(1), 1-16. https://dx.doi.org/10.1186/1752-1505-7-3

Weiss, W. M., Ugueto, A. M., Mahmooth, Z., Murray, L. K., Hall, B. J., Nadison, M., Rasmussen, A., Lee, J. S., Vazzano, A., Bass, J. \& Bolton, P. (2016). Mental health interventions and priorities for research for adult survivors of torture and systematic violence: A review of the literature. Torture, 26(1), 17-44.

World Health Organisation (2010). Mental Health Gap Action Programme: Scaling up care for mental, neurological, and substance use disorders, Geneva: World Health Organisation. 